\title{
Перспективы применения в нейрорегенеративной хирургии обогащенного тромбоцитами фибринового матрикса
}

\author{
В. И. Цымбалюк, И. Г. Васильева
}

Институт нейрохирургии имени А. П. Ромоданова НАМН Украины, г. Киев

\section{Perspectives of application of the fibrin matrix, enhanced by thrombocytes, in neuroregenerative surgery}

\author{
V. I. Tsymbalyuk, I. G. Vasylieva \\ Institute of Neurosurgery named after A. P. Romodanov NAMS of Ukraine, Kyiv
}

\begin{abstract}
Целью современной хирургии является снижение инвазивности и ускорение процесса восстановления. В последние годы в научной литературе введен термин «регенеративная хирургия» и обозначились технологии нового направления. Среди существующих инструментов необходимо выделить матриксы, клетки, биологически активные факторы. В нейрорегенеративной хирургии эффективные матриксы особенно важны. Их использование позволяет заполнять полости с заселением клеток. Они служат проводниками для прорастания нервов. В настоящее время разработано множество матриксов на основе природных и искусственных материалов. Однако в нейрохирургии эти продукты не нашли широкого применения из-за недостаточной биосовместимости. Функционализации материалов для нейрорегенерации посвящено много работ. Хорошие результаты дает сополимеризация матриксов с природными компонентами экстраклеточной среды.
\end{abstract}

Получившие в последнее время популярность обогащенные тромбоцитами биоматериалы лишены многих недостатков искусственных матриксов. Наиболее широко представлены обогащенный тромбоцитами фибрин (ОТФ), обогащенная тромбоцитами плазма (ОТП) и обогащенная факторами роста плазма (ОФРП). Эти материалы биосовместимы, неиммуногенны, легко биодеградируют, не содержат в своем составе чужеродных молекул. Среди их преимуществ также простота получения, что снижает возможность ошибки оператора. Тромбоциты, входящие в состав этих материалов, градиентно высвобождают в экстраклеточную среду биоактивные молекулы, которые способствуют регенерации ткани. Биологически активные молекулы присутствуют в необходимых концентрациях и необходимых сочетаниях, что обеспечивает формирование функционально полноценной ткани. ОТФ можно использовать как наполнитель хирургических полостей, обладающий свойством адгезировать целевые молекулы. Этот матрикс перед использованием можно заселить клетками, насытить факторами дифференцировки или лекарственными препаратами.

Целью настоящей работы является анализ свойств матрикса на основе ОТФ, отличающих его от других природных и искусственных биополимеров и определяющих преи- мущества его использования для нейрорегенерации, а также анализ работ, посвященных применению ОТФ в экспериментальных исследованиях и в клинике.

Недостаточная биосовместимость синтетических матриксов - ограничение к применению в нейрорегене ративной медицине. Актуальным вопросом нейрорегенеративной медицины является создание эффективных матриксов. В настоящее время разработаны матриксы на основе природных материалов - полисахаридов: алгинатов, хитина, хитозана, гепарина, хондроитина; протеогликанов и протеинов: коллагена, желатина, фибрина, кератина, шелкового фиброина, мембраны яичной скорлупы. С использованием методов электро- и магнитоформования получены новые полимерные материалы микро/нанофибриллы на основе полигликолевой, полимолочной, полиакриловой кислот, поли-є-капролактона, поливинилпирролидона, поливинилового спирта, полиэтиленгликоля $[1,2]$

Несмотря на множество существующих матриксов в нейрорегенеративной медицине, их применение ограничено и необходимо их дальнейшее усовершенствование. Основное ограничение к применению - недостаточная биосовместимость. Синтетические матриксы при внутримышечном и подкожном введении через 1 год после имплантации генерируют массированную реакцию на инородное тело, включая и присутствие мультинуклеарных фагоцитов. Матриксы на основе L-ПЛА и L-ПЛА с сополимерами способствуют накоплению инфильтрата. Воспалительный процесс также характеризуется врастанием сосудов и формированием фиброзной ткани в порах матрикса. При имплантации матриксов подкожно и внутримышечно частицы полимера обнаруживаются внутри фагоцитирующих клеток. Остатки матрикса могут обнаруживаться и через 1 год после трансплантации [3]

Биосовместимость матриксов значительно повышается, если они сополимеризуются с компонентами нативного экстраклеточного матрикса - ламинином, коллагеном, желатином. Присутствие компонентов естественного экстраклеточного матрикса в искусственном материале на основе полимолочной кислоты кардинально влияет на пролиферацию, дифференциацию и рост стволовых нейрональных 
клеток, а также синтез этими клетками NGF и VEGF в эксперименте. Функционализация матрикса значительно активизирует элонгацию отростков [4]. Заселение матрикса клетками также улучшает его свойства как тканевой конструкции. При создании пор в полимолочном полимере путем импрегнации клетками слизистой оболочки наблюдается более активное его заселение хондроцитами пульпозного ядра и их пролиферация [5].

Задача нейрорегенерации состоит в необходимости не только обеспечить биомеханическое восстановление и количественное внесение недостающих клеточных элементов, их приживление и функционирование, но и их интегрирование в существующие нейрональные взаимодействия и, соответственно, восполнение недостающих звеньев функционирования. Проведенные исследования определили требования к идеальным матриксам. Матриксы должны быть биосовместимыми, биодеградирующими, иммуноинертными, способными обеспечить диффузию всех молекул, обычно присутствующих в экстраклеточной жидкости, а также локомоцию нейрональных клеток и формирование адекватной нейрональной ткани для замещения тканевого дефекта и восстановления функции [6].

Обогащенный тромбоцитами фибрин - биосовместимый аутоматрикс. ОТФ является новой революционной концепцией применения тромбоцитов в составе фибринового геля [7] и может быть аутологичным материалом, приготовленным непосредственно перед употреблением без химических и биохимических манипуляций. Процедура получения проста и экономически эффективна. Не требуется использование белков животного происхождения. Отсутствуют иммуноконфликты [8]. Структура фибринового геля не препятствует движению экстраклеточной жидкости и содержащихся в ней макромолекул [9]. ОТФ может быть получен и заселен аутоклетками в течение нескольких часов непосредственно при полимеризации, а среда может быть насыщена факторами направленной дифференцировки [10]. Пептидные связи фибрина при росте отростков или локомоции клеток разрушаются секретируемыми протеазами [11]. В состав фибрина входит широкий спектр аминокислот, в том числе и незаменимые - изолейцин, лейцин, лизин, метионин, треонин, триптофан, фенилаланин. Эти аминокислоты после протеолитического расщепления фибрина включаются в анаболический метаболизм клеток [12]. Фибриновый матрикс, в отличие от искусственных полимерных матриксов, обладает специфическими адгезивными свойствами, что способствует привлечению потенциальных нейрональных предшественников [13].

В отсутствие антикоагулянта плазма, обогащенная тромбоцитами, используется как инъекционный обогащенный тромбоцитами фибрин (и-ОТФ). Освобождающиеся после активации тромбоцитов биологически активные компоненты распространяются в транзиентном трехмерном фибриновом матриксе [14]. И-ОТФ вводится интранейрально в качестве жидкого инъекционного матрикса, ОТФ используется в виде полимеризованного гибкого вязкого материала для обертывания вокруг разрывов нервов, возможно также применение этих материалов одновременно [15]. Тканевой фибринолиз расщепляет фибрин, тем самым способствуя высвобождению биологически активных молекул, таких как NGF, BDNF, IGF-1, PDGF, VEGF, HGF, фибронектин, витронектин [16].
Биоактивирующие свойства ОТФ. Многие свойства ОТФ определяются присутствием в его составе тромбоцитов депо биоактивных молекул. Тромбоциты являются траспортерами более 1500 биомолекул, обеспечивающих привлечение нужных для репарации клеток, их активацию и пролиферацию. К ним относятся митогены, нейротрофины, факторы роста: BDNF, NGF, FGF, EGF, PDGF, VEGF, IGF, CTGF, BMP, HGF, а также цитокины, хемокины, адгезивные протеины, протеазы и антипротеазы, ферменты, факторы транскрипции, аденозиндифосфат, серотонин, гистамин [17]. Важно, что эти компоненты присутствуют в биологически обоснованных соотношениях. Для многих биоактивных молекул тромбоцитов известно нейрогенное и нейропротекторное действие в центральной нервной системе взрослого организма. Сигналы BDNF, NGF, FGF, EGF, PDGF, VEGF, IGF, CTGF, BMP, HGF проходят через PI3K/Akt/Nf-kB, MAPK, STAT, PLC и другие эффекторные сигнальные пути. Для каждого фактора не существует уникального гена, который бы он активировал. Активация экспрессии того или иного гена зависит от типа клетки и стадии ее дифференцировки [18].

EGF, FGF - митогены влияют на пролиферативную активность в нейрогенных зонах [19, 20]; IGF-I активизирует пролиферацию и дифференцировку нейрональных стволовых клеток по нейронному и глиальному пути [21]; HGF оказывает влияние на подвижность недифференцированных нейронов на ранних стадиях [22]. PDGF экспрессируется во многих нейрональных клетках, активация его сигнальных путей защищает клетку от апоптоза [23]. CTGF (фактор роста соединительной ткани), опосредующий действие TGF-beta, фиброгенный пептид, кодируемый немедленно ранними генами, имеет значение в регенерации ткани, в частности в поддержании функции гематоэнцефалического барьера и ангиогенеза [24]. VEGF имеет особое значение в защите клеток взрослого мозга от ишемии. ВМР участвует в динамическом регулировании нейрогенеза взрослого мозга сигналами исходящих от микроокружения нервных стволовых клеток [25]. ВМР - морфоген, который действует на близком расстоянии, осуществляя тонкую настройку процесса нейрогенеза, экспансии прогениторов и ускорения дифференцирования прогениторов [26].

NGF и BDNF (факторы роста нервов) активизируют Gбелки семейства RAS, RAP1, G-белки семейства RHO - CDC42 -RAC, сигнальные пути МАРК и PI3K. В результате генерируются различные биологические установки, зависящие от типа клетки и особенностей эффекторных молекул. Сигналы факторов роста нервов определяют жизнеспособность и пролиферацию нейрональных предшественников, рост аксонов, дендритов и синаптогенез, экспрессию функционально важных протеинов [18]. BDNF - нейротрофин во взрослом мозге определяет метаболические установки, способствующие выживанию нейронов, поддержанию функций синапсов, выброса нейромедиаторов, росту аксонов в центральной и периферической нервных системах взрослого организма. Рецептор BDNF TRKB экспрессируется в нейронах руброспинального, ретикулоспинального, вестибулоспинального трактов спинного мозга, таким образом, BDNF является генеральным индуктором роста и миелинизации аксонов [27].

Комплекс биоактивных молекул делает ОТФ не только пассивным материалом, обеспечивающим механическую поддержку нервным клеткам, но и активатором их жизне- 
способности, пролиферации, регулятором специфической функциональной активности.

Нейрорегенерационные и нейропротекторные свойства ОТФ в эксперименте. Наиболее активно в последние годы проводились исследования эффективности применения ОТФ для восстановления повреждений седалищного нерва на различных экспериментальных моделях и с привлечением различных экспериментальных животных. Сравнение результатов восстановления 10-миллиметрового разрыва в седалищном нерве у крыс с использованием аутотрансплантации вывернутой вены, заполненной ОТФ, и пустой вывернутой аутовены показало, что со стороны трансплантата с ОТФ количество миелинизированных аксонов, их диаметр и качество миелинового покрова значительно превосходят таковые со стороны трансплантата без ОТФ [28]. При сравнении результатов трансплантации вены, заполненной ОТФ, и аутотрансплантации фрагмента седалищного нерва отмечено ускорение восстановления и достижение высокого функционального индекса. По мнению авторов, технология использования ОТФ является перспективной альтернативой аутотрансплантации, для выполнения которой необходимо повреждение здорового нерва [29]. Аналогичные результаты получены при использовании силиконовой трубки, заполненной ОТФ и ОТП. Авторы также отмечают улучшение гистоморфометрических параметров: больший диаметр волокна на проксимальном конце и в средней части восстановленного зазора [30]. Применение ОТФ в виде мембраны для обертывания поврежденного участка седалищного нерва с нейротмезисом и последующим хирургическим соединением нерва у крыс способствовало регенерации аксонов и восстановлению функции нерва. Регистрировали более сильный электромиографический сигнал, значительно превосходящую плотность аксонов, а также уменьшение рубцовой ткани. Остатки ОТФ мембраны обнаруживались и через 6 нед после операции. Авторы считают, что ОТФ мембраны является проводником роста аксона [31]. При восстановлении 10-миллиметрового зазора седалищного нерва кроликов с использованием заключенного в трубку из полимолочной кислоты ауто - ОТФ, заселенного шванноподобными клетками, регистрировали значительное увеличение регенерированных волокон, толщины миелинового слоя и проводимости нервного волокна. Матрикс ОТФ, заселенный шванноподобными клетками, является проводником, улучшающим регенерацию нерва [32].

Применение и-ОТФ как дополнительной обработки после сшивания нерва способствует увеличению толщины миелина, числа аксонов и более быстрому восстановлению функций [33]. После применения ОТФ в качестве наполнителя или матрикса для обертывания поврежденного нерва формировались большей плотности аксоны, наступал более ранний электрофизиологический ответ, а также уменьшалась атрофия мышц [15].

На модели компрессии медианного нерва показано, что наложение мембраны из ауто-ОТФ способствует более активной регенерации нервной ткани, проявляющейся в восстановлении функций при проведении теста свободного плавания и теста на беговой дорожке [34].

В эксперименте с использованием введения и-ОТФ непосредственно в спинной мозг при травме позвоночника у крыс отмечали активацию астроцитов, микроглии, экс- прессии PDGF-B и ICAM-1, регенерацию нейронов и ангиогенез, повышение локомоторной активности. При этом продолжительное введение трети дозы оказывало более выраженный терапевтический эффект, чем разовое введение [35]. Метод является альтернативой использованию инъекций рекомбинантных протеинов, трансплантации генмодифицированных клеток и доставке генов с использованием вирусов. Экспериментально показано, что эти способы доставки биоактивных факторов ускоряют восстановление аксонов после травмы спинного мозга, однако они не безопасны в клиническом применении. Так, экспрессия факторов в вирусном геноме удобна тем, что она может продолжаться долго, но их терапевтическое применение ограничено иммуногенностью [36], а также высоким риском развития неоплазии [37].

Использование ОТФ для нейрорегенерации в клинике. Многообещающие результаты применения ОТФ для регенерации периферических нервов в экспериментах на животных активизировали использование этого продукта в клинике. ОТФ применяли для наполнения коллагеновой трубки, соединяющей 12-сантиметровый дефект локтевого нерва [38]; как жидкий динамический матрикс, инфильтрированный периневрально [39], или и-ОТФ для интранейральных инъекций [40].

Позитивные результаты получены при введении и-ОТФ 14 пациентам с карпальным туннельным синдромом средней тяжести, длящимся более 3 мес после травмы медианного нерва. После однократного введения 1 - 2 мл и-ОТФ в регион медианного нерва на проксимальном конце карпального туннеля через 1 мес у 8 пациентов исчезли болевые ощущения, у 3 произошло значительное их снижение. Также наблюдали улучшение функции кисти. Таким образом, одноразовое введение и-ОТФ оказывает позитивное влияние на лечение карпального синдрома, выражающееся в уменьшении реабилитационного срока [39].

При латеризации нижних альвеолярных нервов модифицированным методом с применением ауто-ОТФ и коллагеновой мембраны зарегистрировано ускоренное восстановление чувствительности по сравнению с обычным методом. В группе пациентов, которым операцию проводили обычным методом, чувствительность восстановилась через 12 мес, а в группе пациентам, которым применяли ауто-ОТФ, через 6 мес. Таким образом, применение ауто-ОТФ существенно сокращает период дискомфорта [41].

Для восстановления 12-сантиметрового дефекта локтевого нерва через 3 года и 3 мес после травмы использовали коллагеновую трубку, заполненную ауто-ОТФ. Через 2 года после операции значительно восстановилась чувствительность и моторная функция пальцев, а также снизилась мучительная нейропатическая боль до переносимой [38].

Новая технология применена у 3 пациентов с тяжелыми краниоцеребральными нарушениями. Для репарации нарушений применяли трансплантат: аутомезенхимальные клетки в ауто-ОТФ с остеогенной дифференцировочной средой. У 1 пациента с верхне- и нижнечелюстным радионекрозом и патологическим переломом наблюдали ранний остеогенез, реиннервацию и регенерацию кожи. У 1 пациента с незажившим переломом, дефектом костной ткани и билатеральной парестезией регистрировали регенерацию кости и восстановление нерва. Еще у 1 пациента с массивным дефицитом верхнечелюстной кости после 
применения новой технологии также наблюдали регенерацию костной ткани [42].

\section{Выводы}

Предварительные исследования применения биоматериалов, обогащенных тромбоцитами, подтверждают перспективность их использования для нейрорегенерации. Это решит многие проблемы, над которыми работают биотехнологи: бисовместимость, неиммуногенность, биодеградируемость. Эти материалы легко приготовить по заданным параметрам незадолго до использования. Они могут быть полностью аутологичными, что снимает этические проблемы. Нет необходимости насыщать их искусственными продуктами, стимулирующими биопроцессы. Входящие в состав ОТФ тромбоциты - природные депо факторов репарации нейрогенеза и регуляции функций. Однако еще должна быть выполнена значительная работа по стандартизации режимов получения, хранения, концентрации и введения биологически активных факторов, а также определению показаний и противопоказаний к их использованию.

\section{Підтвердження}

\section{Фінансування}

Це дослідження є фрагментом НДР “Дослідити молекулярно-клітинні взаємодії стовбурових мезенхімальних та нейрональних клітин з компонентами фібринового матриксу in vitro для активізації нейрорегенеративних процесів». Фінансування за рахунок бюджету.

\section{Інформація про внесок кожного учасника}

В. І. Цимбалюк - концепція та дизайн огляду літератури, редагування тексту. І. Г. Васильева - збір та опрацювання матеріалу, написання тексту.

Всі автори прочитали і схвалили остаточний варіант рукопису.

\section{Конфлікт інтересів}

Автори, які взяли участь в цьому дослідженні, заявили, що у них немає конфлікту інтересів щодо цього рукопису.

\section{Згода на публікацію}

Всі автори дали згоду на публікацію цього рукопису.

\section{References}

1. Edgar L, McNamara K, Wong T, Tamburrini R, Katari R, Orlando G. Hete rogeneity of Scaffold Biomaterials in Tissue Engineering. Materials (Basel). 2016 May 3;9(5). pii: E332. http://doi.org/10.3390/ma9050332.

2. Bhattarai DP, Aguilar LE, Park CH, Kim CS. A Review on Properties of Natural and Synthetic Based Electrospun Fibrous Materials for Bone Tissue Engineering.Membranes (Basel). 2018 Aug 14; 8(3). pii: E62. http:// doi.org/10.3390/membranes8030062.

3. Beumer GJ, van Blitterswijk CA, Ponec M. Degradative behaviour of polymeric matrices in (sub)dermal and muscle tissue of the rat: a quantitative study. Biomaterials. 1994 Jun;15(7):551-9. PMID: 7918908

4. Alessandri M, Lizzo G, Gualandi C, Mangano C, Giuliani A, Focarete ML, et al. Influence of biological matrix and artificial electrospun scaffolds on proliferation, differentiation and trophic factor synthesis of rat embryonic stem cells. Matrix Biol. 2014 Jan;33:68-76. http://doi.org/10.1016/j.matbio.2013.08.001.

5. Kim SH, Song JE, Lee D, Khang G. Development of poly (lactide-co-glycolide) scaffold-impregnated small intestinal submucosa with pores that stimulate extracellular matrix production in disc regeneration. J Tissue Eng Regen Med. 2014 Apr;8(4):279-90. http://doi.org/10.1002/term.1520.

6. Mosher CZ, Spalazzi JP, Lu HH. Stratified scaffold design for engineering composite tissues. Methods. 2015 Aug;84:99-102. http://doi.org/10.1016/j. ymeth.2015.03.029.

7. Dohan DM, Choukroun J, Diss A, Dohan SL, Dohan AJ, Mouhyi J, et al. Platelet-rich fibrin (PRF): A second-generation platelet concentrate. Part
I: Technological concepts and evolution Oral Surg Oral Med Oral Pathol Oral Radiol Endod. 2006 Mar;101(3):e37-44. http://doi.org/10.1016/j. tripleo.2005.07.008

8. Piccin A, Di Pierro AM, Canzian L, Primerano M, Corvetta D, Negri G, et al. Platelet gel: a new therapeutic tool with great potential. Blood Transfus. 2017 Jul;15(4):333-40. doi: 10.2450/2016.0038-16. Epub 2016 Jul 25.

9.Schär MO, Diaz-Romero J, Kohl S, Zumstein MA, Nesic D. Platelet-rich concentrates differentially release growth factors and induce cell migration in vitro. Clin Orthop Relat Res. 2015 May;473(5):1635-43. http://doi. org/10.1007/s11999-015-4192-2.

10. Bahmanpour S, Ghasemi M, Sadeghi-Naini M, Kashani IR. Effects of Platelet-Rich Plasma \& Platelet-Rich Fibrin with and without Stromal Cell-Derived Factor-1 on Repairing Full-Thickness Cartilage Defects in Knees of Rabbits. Iran J Med Sci. 2016 Nov;41(6):507-17. PMID: 27853331

11. Isobe K, Watanebe T, Kawabata H, Kitamura Y, Okudera T, Okudera H, et al. Mechanical and degradation properties of advanced platelet-rich fibrin (A-PRF), concentrated growth factors (CGF), and platelet-poor plasma-derived fibrin (PPTF). Int J Implant Dent. 2017 Dec;3(1):17. http://doi. org/10.1186/s40729-017-0081-7.

12. Xie X, Zhang C, Tuan RS. Biology of platelet-rich plasma and its clinical application in cartilage repair. Arthritis Res Ther. 2014 Feb 25;16(1):204. http://doi.org/10.1186/ar4493.

13. Wu CL, Lee SS, Tsai CH, Lu KH, Zhao JH, Chang YC. Platelet-rich fibrin increases cell attachment, proliferation and collagen-related protein expression of human osteoblasts. Aust Dent J. 2012 Jun;57(2):207-12. http://doi. org/10.1111/j.1834-7819.2012.01686.x.

14. Wang X, Zhang Y, Choukroun J, Ghanaati S, Miron RJ. Behavior of Gingival Fibroblasts on Titanium Implant Surfaces in Combination with either Injectable-PRF or PRP. Int J Mol Sci. 2017 Feb 4;18(2). pii: E331 http:// doi.org/10.3390/ijms18020331.

15. Sánchez M, Anitua E, Delgado D, Sanchez P, Prado R, Orive G, et al. Platelet-rich plasma, a source of autologous growth factors and biomimetic scaffold for peripheral nerve regeneration. Expert Opin Biol Ther. 2017 Feb;17(2):197-212. http://doi.org/10.1080/14712598.2017.1259409.

16. Roh YH, Kim W, Park KU, Oh JH. Cytokine-release kinetics of plateletrich plasma according to various activation protocols. Bone Joint Res. 2016 Feb;5(2):37-45. http://doi.org/10.1302/2046-3758.52.2000540.

17. Mussano F, Genova T, Munaron L, Petrillo S, Erovigni F,Carossa S. Cytokine, chemokine, and growth factor profile of platelet-rich plasma. Platelets. 2016 Jul;27(5):467-71. http://doi.org/10.3109/09537104.2016.1143922.

18. Huang EJ, Reichardt LF. Trk receptors: roles in neuronal signal transduction. Annu Rev Biochem. 2003 Mar 27;72:609-42. http://doi.org/10.1146/ annurev.biochem.72.121801.161629

19. Galvez-Contreras AY, Quiñones-Hinojosa A, Gonzalez-Perez O. The role of EGFR and ErbB family related proteins in the oligodendrocyte specification in germinal niches of the adult mammalian brain. Front Cell Neurosci. 2013 Dec 17;7:258. http://doi.org/10.3389/fncel.2013.00258.

20. Woodbury ME, Ikezu T. Fibroblast growth factor-2 signaling in neurogenesis and neurodegeneration. J Neuroimmune Pharmacol. 2014 Mar;9(2):92101. http://doi.org/10.1007/s11481-013-9501-5.

21. Nieto-Estévez V, Defterali Ç, Vicario-Abejón C. IGF-I: A Key Growth Factor that Regulates Neurogenesis and Synaptogenesis from Embryonic to Adult Stages of the Brain. Front Neurosci. 2016 Feb 23;10:52. http://doi. org/10.3389/fnins.2016.00052.

22. Cacci E, Salani M, Anastasi S, Perroteau I, Poiana G, Biagioni S,et al. Hepatocyte growth factor stimulates cell motility in cultures of the striatal progenitor cells ST14A. J Neurosci Res. 2003 Dec 1;74(5):760-8. http:// doi.org/10.1002/jnr. 10799

23.Funa K, Sasahara M. The roles of PDGF in development and during neurogenesis in the normal and diseased nervous system. J Neuroimmune Pharmacol. 2014 Mar;9(2):168-81. http://doi.org/10.1007/s11481-013-9479-z.

24. Schwab JM, Beschorner R, Nguyen TD, Meyermann R, Schluesener HJ. Differential cellular accumulation of connective tissue growth factor defines a subset of reactive astrocytes, invading fibroblasts, and endothelial cells following central nervous system injury in rats and humans. J Neurotrauma. 2001 Apr;18(4):377-88. http://doi.org/10.1089/089771501750170930]

25. Sun FY, Guo X. Molecular and cellular mechanisms of neuroprotection by vascular endothelial growth factor. J Neurosci Res. 2005 Jan 1-15;79(12):180-4. http://doi.org/10.1002/jnr.20321

26. Choe Y, Pleasure SJ, Mira H. Control of Adult Neurogenesis by Short-Range Morphogenic-Signaling Molecules. Cold Spring Harb Perspect Biol. 2015 Dec 4;8(3):a018887. http://doi.org/10.1101/cshperspect.a018887. 
27. Keefe KM, Sheikh IS, Smith GM. Targeting Neurotrophins to Specific Populations of Neurons: NGF, BDNF, and NT-3 and Their Relevance for Treatment of Spinal Cord Injury. Int J Mol Sci. 2017 Mar 3;18(3). pii: E548. http://doi.org/10.3390/ijms18030548.]

28. Kim JY, Jeon WJ, Kim DH, Rhyu IJ, Kim YH, Youn I, et al. An insideout vein graft filled with platelet-rich plasma for repair of a short sciatic nerve defect in rats. Neural Regen Res. 2014;9:1351-1357. http://doi. org/10.4103/1673-5374.137587

29. Sabongi RG, De Rizzo LALM, Fernandes M, Valente SG, Gomes dos Santos JB, Faloppa F, et al. Nerve regeneration: is there an alternative to nervous graft? J Reconstr Microsurg. 2014 Nov;30(9):607-16. http://doi. org/10.1055/s-0034-1372477.

30. Lichtenfels M, Colomé L, Sebben AD, Braga-Silva J. Effect of Platelet Rich Plasma and Platelet Rich Fibrin on sciatic nerve regeneration in a rat model. Microsurgery. 2013 Jul;33(5):383-90. http://doi.org/10.1002/micr.22105.

31. Giannessi E, Coli A, Stornelli MR, Miragliotta V, Pirone A, Lenzi C, et al. An autologously generated platelet-rich plasma suturable membrane may enhance peripheral nerve regeneration after neurorraphy in an acute injury model of sciatic nerve neurotmesis. J Reconstr Microsurg. 2014 Nov;30(9):617-26. http://doi.org/10.1055/s-0034-1372483.

32. Ye F, Li H, Qiao G, Chen F, Tao H, Ji A, et al. Platelet-rich plasma gel in combination with Schwann cells for repair of sciatic nerve injury. Neural Regen Res. 2012 Oct 15;7(29):2286-92. http://doi.org/10.3969/j.issn.16735374.2012.29.007.

33. Sariguney Y, Yavuzer R, Elmas C, Yenicesu I, Bolay H, Atabay K. Effect of platelet-rich plasma on peripheral nerve regeneration. J Reconstr Microsurg. 2008 Apr;24(3):159-67. http://doi.org/10.1055/s-2008-1076752.

34. Bertolini GRF, Kakihata CMM, Peretti AL, Bernardino GR, Karvat J, Silva JLC, et al. Effects of the platelet-rich fibrin associated with physical exercise in a model of median nerve compression. Motriz, Rio Claro. 2017;23(4): e1017100. http://doi.org/10.1590/S1980-6574201700040010.

35. Chen NF, Sung CS, Wen ZH, Chen CH, Feng CW, Hung HC, et al. Therapeutic Effect of Platelet-Rich Plasma in Rat Spinal Cord Injuries. Front Neurosci. 2018 Apr 23;12:252. http://doi.org/10.3389/fnins.2018.00252.
36. Peden CS, Burger C, Muzyczka N, Mandel RJ Circulating anti-wild-type adeno-associated virus type 2 (AAV2) antibodies inhibit recombinant AAV2 (rAAV2)-mediated, but not rAAV5-mediated, gene transfer in the brain. J Virol. 2004 Jun;78(12):6344-59. http://doi.org/10.1128/JVI.78.12.63446359.2004

37. Marshall E. Gene therapy. Second child in French trial is found to have leukemia. Science. 2003 Jan 17;299(5605):320. http://doi.org/10.1126/science.299.5605.320

38. Kuffler DP, Reyes O, Sosa IJ, Santiago-Figueroa J. Neurological recovery across a $12-\mathrm{cm}-$ long ulnar nerve gap repaired 3.25 years post trauma: case report. Neurosurgery. 2011 Dec;69(6):E1321-6. http://doi.org/10.1227/ NEU.0b013e31822a9fd2

39. Malahias MA, Johnson EO, Babis GC, Nikolaou VS. Single injection of platelet-rich plasma as a novel treatment of carpal tunnel syndrome. Neural Regen Res. 2015 Nov;10(11):1856-9. http://doi.org/10.4103/16735374.165322 .

40. Scala M, Mereu P, Spagnolo F, Massa M, Barla A, Mosci S, et al. The use of platelet-rich plasma gel in patients with mixed tumour undergoing superficial parotidectomy: a randomized study. In Vivo. 2014 Jan-Feb;28(1):1214. PMID: 24425846

41. Khojasteh A, Hosseinpour S, Nazeman P, Dehghan MM. The effect of a platelet-rich fibrin conduit on neurosensory recovery followinginferior alveolar nerve lateralization: a preliminary clinical study. Int J Oral Maxillofac Surg. 2016 Oct;45(10):1303-8 http://doi.org/10.1016/j.ijom.2016.06.003.

42. Mendonça JJ, Juiz-Lopez P. Regenerative facial reconstruction of terminal stage osteoradionecrosis and other advanced craniofacial diseases with adult cultured stem and progenitor cells.Plast Reconstr Surg. 2010 Nov;126(5):1699-709. http://doi.org/10.1097/PRS.0b013e3181f24164.

Надійшла19.12.2018 